\title{
Clinical and Angiographic Comparison of Matched Patients With Successful Directional Coronary Atherectomy or Stent Implantation for Primary Coronary Artery Lesions
}

\author{
VICTOR A. UMANS, MD, PHD, REIN MELKERT, MD, DAVID P. FOLEY, MB, MRCPI, PHD, \\ PATRICK W. SERRUYS, MD, PHD, FACC
}

Rotterdam, The Netherlands

Objectives. This study was designed to compare the long-term clinical and angiograph tit effects of successful directional atherectomy and stent implan ation and to examine whether restenosis is related to the mechansm of lumen improvement as well as the extent of luxten gain.

Background. Directional atherectomy and coronary stent inplantation hove been shown to achice a nore optimal immediate result that may lead to a more favorable long-term angiographic outcome and fewer target vessel revascularizations than does angioplasty. However, it remains to be determined whether one of the devices used in these interventions provides consistently better results than the other.

Methods. To allow meaningful comparisons, a prospectively collected series of 117 patients successfully treated with atherectomy were individually matched with a prospectively collected series of 117 patients successfully treated with stent implantation. Matching for saseline characteristics identified patients with identical lesion location and lesion severity, and immediate and late angiographic and clinical outcome were compared. To evalu. ate the possibility of a procedure effect on restenosis, patients were further matched for both immediate angiographic outcome and baseline characteristics, providing 150 matched patients for comparison. As confirmatory analysis, multivariate models were constructed to predict late lumen diameter.

The importancs of optimization of acute interventional results with all treatrist devices is now well recognized (1-13). However, it renains to be determined whether the extent of the vessel wall healing process after an intracoronary intervention, and herefore the angiograptic outcome, is also influenced by the specific mechanism of an interventional device. An initial exploration of such a relation between device specticty and restenosis, using the loss index as an angio-

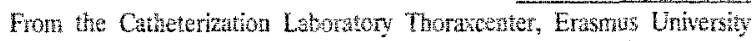

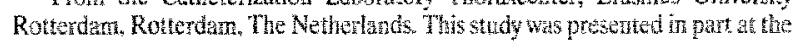

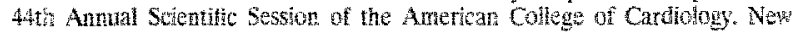
Oritons, Lowisiama, March 1995.

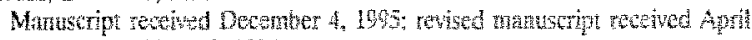
10. 1596.

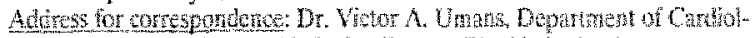

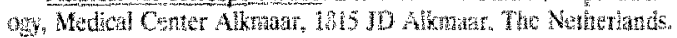

Results. Matching resulted in two comparable groups with equivalent baseline clinical and stenosis characteristics $(n=117$ pairs). Atherectomy led to a smaller immediate gain than stenting and, because late loss was similar in both groups, stenting resulted in a larger late lumen $(1.96 \pm 0.51$ vs. $1.66 \pm 0.55 \mathrm{~mm}$, p $<0,0$ M1). When patients were matched for immediate gain and baseline characteristics ( $\mathrm{n}=75$ pairs), Iumen loss was more pronounced after atherectomy, and thus the minimal lumen diameter at follow-up differed significantly between the two groups $(1.66 \pm 0.53$ vs. $1.90 \pm 0.47 \mathrm{~mm}, p=0.004)$. This beneficial angiographic effect of stenting was accompanied by a reduced need for repeat interventions. Multivariate analysis confirmed the independent effect of the interventional device used, whereby less Ioss and greater lumen diameter at follow-up were predicted for stent implantation than for atherectomy:

Conclusions. Successful stent implantation provided a wore favorable long-term angiographic cutcome and lower rates of restenosis and need for target lesion revascularization than did atherectomy. This favorable effect of stenting not only is related to a larger immediate gain, but also seems to attenuate late lumen loss.

(J Am Coll Cardiol 1996;28:637-44)

graphi correlate of the "proportional injury model" $(1,2)$, did not dete : such an independent effect even wiven the results were corrected for the difference in inmedinte gain, which has been shown $(1,4,5,7,9)$ to be the nost important predictor of restenosic, In contrast, our group has bypothesized that the varying mechanisms of action of interventional devices might induce varying tiogrees of lunen renarrowing in patents matched for clinical and lesion characteristics $(7,8)$. To try to reconcile these two viewpoints, an automated case-matching method in which pations are matched for baseline and procedural characteristics was developed to explore differences in late outcome between patums trentad with uen devices. An additional advantage of this matching technique is the possibility of assessing lory-term resuls without a comeanify between immedate gain and interventional device.

Recendy, Hrectiona atherectomy and coronary stenting 
were compared with conventional balloon angioplasty for their ability to reduce restenosis (10-13). Although both techniques achieved a greater lumen gain than did balloon angioplasty, only stenting reduced the restenosis rate significantly $(12,13)$. Whereas these trials showed a comparable lumen gain after atherectomy and stenting we recognized that the difference in lumen renarrowing after atherectomy and stenting may relate to either the extent or the mechanism (debulking versus scaffolding) of lumen improvement.

In this study we comparatively evaluated successful directional atherectomy and stent implantation in a prospectively collected series of 234 patients by using the previously validated matching methodology. By matching for both immediate angiographic outcome and baseline charmcteristics, we extended our observations and tested the hypothesis that each interventional device has unique properties with respect to lumen renarrowing that are independent of cinicai, angiographic or procedural characteristics.

\section{Methods}

Atherectomy group. From September 1989 through March 1994, 208 patients underwent 214 directional atherectomy procedures for native coronary or bypass graft lesions. Of these, 150 consecutive patients (who underwent 157 successful procedures) have had a 6 -month follow-up angiographic study (angiographic follow-up rate $90 \%$ ). For the purpose of this study, the late outcome of atherectomy was compared with that of stenting for consecutive native primary lcsions. Thercfore, patients with restenotic lesions and patients with a subacute coronary occlusion of $<24 \mathrm{~h}$ duration were excluded. Of the 150 patients, 3 were treated for a lesion in a venous bypass graft and 13 underwent atherectomy for 18 restenotic lesions after previous angioplasty. Thus, 134 patients who underwent 136 successful atherectom procedures for native primary coronary artery disease were cligible for matching.

Stent group. From Janury 1990 through March 1994, 240 patients were successfully treated by Palmaz-Schatz stent implantation at the Thoraxcenter. Of these, 213 patients had a stent electively implanted for a primary coronary lesion without cinical sequelae (i.e., no subacute ocdusion). Of these, 179 consecutve patients have had a 6month follow-up angiographic sudy and were thus eligible for matching. Patients were selected for drectional atherectomy or stent implantation when they presented with a stenosis in a proximal nontortuous coronary artery with a reference diameter $>2.5 \mathrm{~mm}$. Al patents gave intorned consent and wore prospectively scheduled for ingiography at 6 months, a procedure completed by $90 \%$ of the pationts. The study was appreved by the hospitals Institutional Reviow Board. Nll clinical and thyographic data were ollected prospectively.

Afrrectony and stenting procedure. The athetrectomy

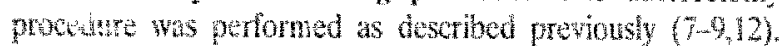
Brofy, the atherectony heve was directod over yude wre and postononed aross the stenosis. The suppor balloon was

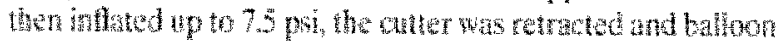

inflation pressure was increased to maximally 45 psi. The driving motor was activated and the rotating cutter was slowly advanced to cut and collect the protruding atherosclerotic lesion in the collecting chamber located at the tip of the catheter. After every pass the balloon was deflated and either removed or repositioned. A $6 \mathrm{t}$ atherectomy device was used in $34 \%$ of patients and a $7 \mathrm{~F}$ device in $66 \%$. Adjunctive balloon dilation was performed in $23 \%$. Although an optimal angiographic result was sought for cach lesion treated, the procedure was considered angiographically successful when the residual diameter stenosis was $<50 \%$ after tissue retrieval. This classic definition of success should be viewed in historical perspective; currently a lumen gain of $\geq 0.7 \mathrm{~mm}$ or a postatherectomy diameter stenosis $<20 \%$ may be deemed necessary bcforc a procedure is considered successful, as recently observed in retrospective analyses (2) and as defined in the ongoing atherectomy trials (Balloon vs. Optimal Atherectomy Trial [BOAT], Optimal Atherectomy Restenosis Study [OARS], European Carvedilol Restenosis trial [EUROCARE]). Such a result was reached in $22 \%$ of cases. Stenting was performed by the femoral approach and the stent was delivered by inflation of the balloon that contained the crimped stent. The following Palmaz-Schatz stents were implanted: $3.0 \mathrm{~mm}(46 \%), 3.5 \mathrm{~mm}(39 \%)$ and $4.0 \mathrm{~mm}(15 \%)$. Additional intrastent balloon dilation was performed in 27 patients (23\%). Anticoagulation during and after stent implantation was given according to the protocol and contaned heparin, dextran, dipyridamole, aspirin and warfarin for 3 months. Patients were monitored as described earlier (7$9,12,13)$.

Quantitative coronary angingraphy. Quantitative analysis of the coronary segments was performed with the computerbased Coronary Angiography Analysis System (CAAS), which has been previously validated and described in detail $(8,12,14,15)$. In particular, as uracy and precision measurements ior in vivo phantom seasurements are 0.09 and 0.23 (16). In essence, boundaries of a selected coronary artery segment are defected automatically from optically magnified and video-digitized regions of interest ( $512 \times 512$ pixels) of a cine frame. The absolute diameter of the stenosis in $\mathrm{mm}$ is determined by using the guiding catheter as a scaling device for calibration. The external diameter of each individual catheter is measured by a precision micrometer with a tolerance of $0.001 \mathrm{~mm}$. Correction for pincushion distortion is performed. Computer estimation of the original dimension of the artery at the site of the obstruction provides an interpotated reterance diamezer. All other vanables (e.g., immediate gain, late loss) are then collulated.

To standardize the method of analysis of the interventional and follow ap angiogram, the following meisures were routinely applied. First the X-ray gantry was exacty repositioned to the sethes that were doumbnted at the time of the

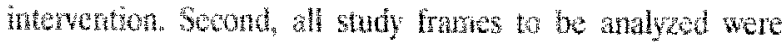

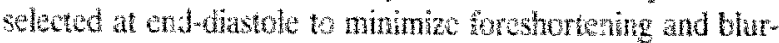

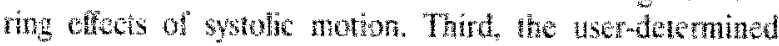

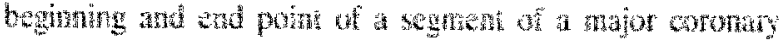


artery were identified according to the detinitions of the American Heart Association (17). Finally, Polaroid photographs were taken of the video image with the detected contours superimposed to ensure that the analyses were performed on the same coronary segments. Intracoronary isosorbide dinitrate (1 to $3 \mathrm{mg}$ ) was given before and after intervention. Administration of intracoronary nitrates was recommended before follow-up angiography.

Matching process. The process of matching for clinical and angiographic characteristics (see Appendix) has been previously described $(7,8,15)$. Clinical factors such as gender, diabetes, hypercholesterolemia (18) and nonexertional angina were taken into account. The coronary artery tree was subdivided into 15 segments according to American Heart Association guidelines and the lesions were individually matched according to stenosis location and reference diameter and mininal lumen diameter. The principles of matching by quantitative angiography are threefold: 1) The angiographic dimensions of matched lesions are assumed to be "identical," 2) the observed difference between the two "identical" lesions must be within the range of the reproducibility of the CAAS analysis $(0.1 \mathrm{~mm}$ [=1 SD]), and 3) the reference diameter of the lesions to be matched is selected within a range of $\pm 0.3 \mathrm{~mm}(=3 \mathrm{SD})$ $(8,14,16)$. Clinical factors such as gender, diabates, hypercholesterolemia and nonexertional angina were taken into account The automated matching program identified 117 prospectively collected patients with 117 coronary artery lesions treated stccessfully with atherectomy who could be individually matched with 117 prospectively collected conseculive patients treateờ susccessfully with stenting (diameter stenosis $<50 \%$ on visual inspection). The remaining patients $(13 \%)$ of the atherectoniy cohort could not be matched because no identical patient with stenting was found according to the prespecified mat thing criteria. The clinical and angiographic details of the two groups are given in Table 1.

To extend our observations and to test the hypothesis that each interventional device has unique properties with respect to lumen renarrowing that are independe at of vessel size and lesion severity and lumen gain, matching for immediate procedural result as well as baseline characteristics yieided 150 matched patients.

Dinical follow-sup. All natients were prosnectively seen at the outpatient clinical at regular time interals during a 7-month follow-up period. The clinical end points were death, myocardial infarction, coronary artery bypass grafting and repeat percutaneous intervention. Death was defined to include all death. Myocardial infarction was defined as the occurrence of a new abnormal $Q$ wave and an increase in creatine kinase more than twice the upper limit of normal. Revascularization of the target lesion was defined as angioplasty or bypass surgery performed because of restenosis of the target lesion in association with angina or objective avidence of myocardial ischemia, or both.

Statistical analysis, The unit of andysis reported here is the pationt. All values are expressed as nnean value $+1 \mathrm{SD}$. Coxparisonc of continums vatribles thetween the two groups
Table 1. Clinical and Angiographic Characteristics of the 234 Study Patients

\begin{tabular}{lccc}
\hline & $\begin{array}{c}\text { Atherectomy } \\
(\mathrm{n}=117)\end{array}$ & $\begin{array}{c}\text { Stent } \\
(\mathrm{n}=117)\end{array}$ & $\mathrm{p}$ Value \\
\hline Age (yr) & $58 \pm 11$ & $57 \pm 10$ & 0.71 \\
Male & $76 \%$ & $81 \%$ & 0.34 \\
Vessel treated & & & \\
LAD & $77 \%$ & $77 \%$ & 1.0 \\
LCx & $8 \%$ & $8 \%$ & 1.0 \\
RCA & $15 \%$ & $15 \%$ & 1.0 \\
Nonexertional angina & 38 & 48 & 0.11 \\
Previous intarction & $25 \%$ & $18 \%$ & 0.20 \\
Previous CABG & 0 & 0 & 1.0 \\
Diabetes & $6 \%$ & $9 \%$ & 0.33 \\
Hyperchotesterolemia & $24 \%$ & $23 \%$ & 0.10 \\
\hline
\end{tabular}

Data presented are mean value $\pm S D$ or percent of patient group. $\mathrm{CABG}=$ coronary artery bypass grafting; $\mathrm{LAD}=$ left anterior descending coronary attery; $\mathrm{LCX}=$ left circumflex coronary antery; $\mathrm{RCA}=$ right coronary antery.

were performed by using the paired Student $t$ test. Selected angiographic variables were evaluated by univariate regression andysis for their correlation with absolute lumen loss and minimal lumen diameter at follow-up. Multivariate stepwise regression analysis using a commercially available statistical software package (SAS, SAS Institute Inc.) was utilized to take into account the influence of lesion location, preprocedurai minimal lumen diameter, acute lumen gain and vessel size in evaluating their contribution to the minimal lumen diameter at follow-up and late lomen loss. Differences between catteguric variables were tested with the chi-square and Fisher exact tests as appropriate. Target lesion revascularization was analyzed by means of Kaplan-Meier survival curves, with differences between the two groups compated by Wilcoxon test. Differerices were considered statistically significant where the $p$ value was $<0.05$.

\section{Results}

Outcome of the matching process (Table 1). The automaied computer matehing program provided 117 pairs of patients-117 with successful atherectomy and 117 with successful stentine-with comparable clinical and angiographic characteristics (iesion location and severity). The 234 patients wers predominantly male with a mean age $\pm S D$ of $57 \pm 11$ years. Patients were predominantly treated for stable angina according to the American Heart Association classification. By matching design no difference in lesion distribution exists between the atherectony and stent group: left anterior deseending artery $(77 \%$ vs. $77 \%)$, right coronary artery $(15 \%$ is. $15 \%$ ) and left circumfex artery ( $8 \%$ w. $8 \%$ ). No diferences between groups were found for risk factors for coronary artery disenge or preceding catdiovascular events such as myocardial infaretion or bypass surgery. By study design, wo significunt differences betwen the atherectoniy and stent groups were found in beseline quantitative angiographic variables: mean vessel size (3.09 \pm 0.45 vs. $3.10 \pm 0.44 \mathrm{~mm}$, praprocedural 
Table 2. Comparison of Quantitative Angiographic Data of 234 Matched Patients Who Underwent Atherectomy or Stent Implantation for Similar Lesion Severity

\begin{tabular}{|c|c|c|c|}
\hline & $\begin{array}{l}\text { Atherectomy } \\
(n=117)\end{array}$ & $\begin{array}{l}\text { Stenting } \\
(\mathrm{n}=117)\end{array}$ & $p$ Value \\
\hline $\begin{array}{l}\text { Reference dianeter pre (mm) } \\
\text { ivinimal lumen diamete (nm) }\end{array}$ & $3.09 \pm 0.45$ & $3.10 \pm 0.44$ & 0.92 \\
\hline Pre & $1.12+029$ & $1.12 \pm 0.27$ & 0.97 \\
\hline Post & $2.32 \pm 0.41$ & $2.53 \pm 0.3^{7}$ & 0.001 \\
\hline follow-up & $1.66 \pm 0.55$ & $1.96+0.51$ & 0.000 \\
\hline \multicolumn{4}{|l|}{ Diameter stenosis (\%) } \\
\hline Pre & $64 \pm 8$ & $64 \pm 8$ & 0.0001 \\
\hline Post & $28 \pm 10$ & $21 \pm 7$ & 0.0001 \\
\hline Follow-up & $44 \pm 17$ & $35 \pm 13$ & 0.0001 \\
\hline \multicolumn{4}{|l|}{ Lumen loss (mm) } \\
\hline Absolute & $0.66 \pm 0.58$ & $0.57+0.47$ & 0.22 \\
\hline Relative & $0.22 \pm 0.19$ & $0.19 \pm 0.15$ & 0.18 \\
\hline Restenosis rate (\%) & 36 & 14 & $0.1^{\prime / 5}$ \\
\hline Lesion lengh (mm) & $6.83 \pm 2.54$ & $7.23 \pm 2.05$ & 0.82 \\
\hline Curvature value pre & $14.5 \pm 6.3$ & $14.7 \pm 5.9$ & $0.9 ?$ \\
\hline Symmetry index pre & $0.45 \pm 0.25$ & $0.37 \pm 0.25$ & 0.79 \\
\hline Area plaçuo pre $\left(\mathrm{mm}^{2}\right)$ & $9.53 \pm 4.64$ & $9.46 \pm 4.00$ & 0.83 \\
\hline
\end{tabular}

Data presented are mean value $\pm \mathrm{SD}$. Post $=$ after intervention; pre $=$ before intervention.

minimal lumen diameter $(1.12 \pm 0.29 \mathrm{~mm}$ vs. $1.12 \pm 0.27 \mathrm{~mm})$ and percent diameter stenosis $(64 \pm 8 \%$ v. $64 \pm 8 \%)$, respectively.

Immediate and late outcome after matching for baseline characteristics (Tables 2 and 3, Fig. 1). The reference dianeters were not significantly different after atherectomy or stenting ( $3.23 \pm 0.46$ vs. $3.22 \pm 0.41 \mathrm{~mm}, \mathrm{p}=0.83$ ). Directional atherectomy resulted in a smaller immediate gain in minimal lumen diameter than did coronary stenting $(1.20 \pm 0.46 \mathrm{vs}$. $1.41 \pm 0.39 \mathrm{~mm}, \mathrm{p}=0.002$ ) with a consequentiy lower postprocedural minimal lumen diameter $(2.32 \pm 0.41 \mathrm{~mm}$ vs. $\left.2.53 \pm 0.37 \mathrm{~mm}_{1} \mathrm{p}<0.001\right)$ and conconitantly higher percent dianeter stenosis ( $28 \pm 10 \%$ vs. $21 \pm 7 \%, p<0.001$ ). Because absolute loss during follow-up did not differ significantly between the atherectomy and stent groups $(0.66 \pm 0.58$ vs. $0.57 \pm 0.53 \mathrm{~mm}, \mathrm{p}=0.22$ ), the initial favorable inmediate result after stenting was maintained during follow-up. Thus, the minimal lumen diameter at follow-up after atherectomy was significantly lower than after stenting (1.66 \pm 0.55 vs. $1.56 \pm 0.51 \mathrm{~mm}, \mathrm{p}<0.0001)$. Accordingly, atherectony

Table 3. Long-Term Clinical Outcome After Successful Atherectony and Stent Inplantation in Matched Patients

\begin{tabular}{lccc}
\hline & $\begin{array}{c}\text { Atheretomy } \\
(\mathrm{n}=117)\end{array}$ & $\begin{array}{c}\text { Sterting } \\
(\mathrm{n}-117)\end{array}$ & $\rho$ Value \\
\hline Death & 0 & 0 & 1.0 \\
Wyocardial intarcion & $3 \%$ & $3 \%$ & 1.0 \\
Cotonary attery bypass surgery & $3 \%$ & $2 \%$ & $0.6 \%$ \\
Repeat PTCA & $20 \%$ & $10 \%$ & 0.07 \\
\hline
\end{tabular}

Daka presented are perent of paticnt group. PTCA = percutaneous

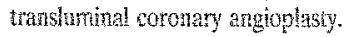
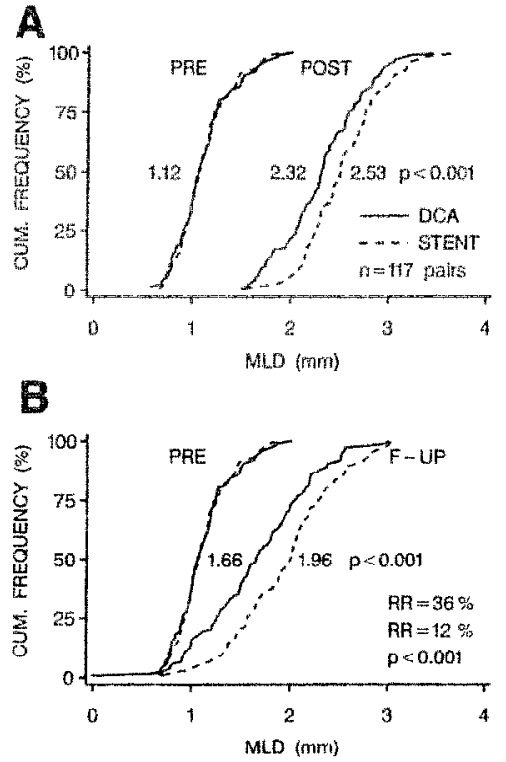

Figure 1. Cumulative (CUM.) frequency curves illustrate the immediate (A) and follow-up (F-UP) (B) effects on minimal lumen diameter (MLD) of directional coronary atherectomy (DCA) and stent implantation in patients matched for lesion location and severity $(n=117$ pairs). As shown, the matching process was adequate, with superimposition of the distribution frequency curves of the minimal lumen diameter before atherectomy and stenting indicating similar preprocedural stenosis severily. POST $=$ after the procedure; PRE $=-$ before the procedure; $R R=$ restenosis rate (diameter stenosis at follow-up $<50 \%$ ).

yielded a lower net gain $(0.54 \pm 0.58$ vs. $0.84 \pm 0.53, \mathrm{p}<$ $0.0001)$ and a higher percent diameter stenosis at follow-up (44 $\pm 16 \%$ vs. $35 \pm 13 \%, \mathrm{p}<0.0001)$. The restenosis rate (diameter stenosis at follow-up $>50 \%$ ) after stenting was significantly lower than after atherectomy $(14 \%$ vs. $36 \%, \mathrm{p}=$ 0.0053 ). These results were also found in the subgroup analysis for optinally treated patients (minimal lumen diameter $>2.75 \mathrm{~mm}, \mathrm{n}=1 \mathrm{~s}$ pairs). Althongh there was a trend for a higher postprocedural minimal lumen diameter after atherectomy than after stenting $(2.96 \pm 0.17 \mathrm{w} .2 .74 \pm 0.5 \mathrm{~mm}, \mathrm{p}=$ $0.03)$ in these patients, late loss was neary two times higher in the atherectomy group (1.03 \pm 0.59 vs. $0.58 \pm 0.62 \mathrm{~mm}, \mathrm{p}=$ 0.04 ), yielding a lower, but not siguifcantly difierent, final minimal lumen diameter in the patients with atherectomy than in those with stenting $(1.93 \pm 0.55$ vs. $2.16+0.53 \mathrm{~mm}, \mathrm{p}=$ $0.22)$.

The late clinical follow-up was atso more favorable for patients with stenting and showed a reduced need for repeat revascularization. Clinical follow-up data were avalable in $100 \%$ of the patients. No deaths were observed and significantly fewer patients with stenting than patients with atherectomy required target lesion revascularization (12\% vs. $23 \%$, $p=0.05$ ) (Fig. 2). In multivariate analysis, lesion location, vessel size, minimal lumen diameter before intervention, absolute gain and type of interventional device were identified as independent predictors of the absolnte lumen loss and minimal 


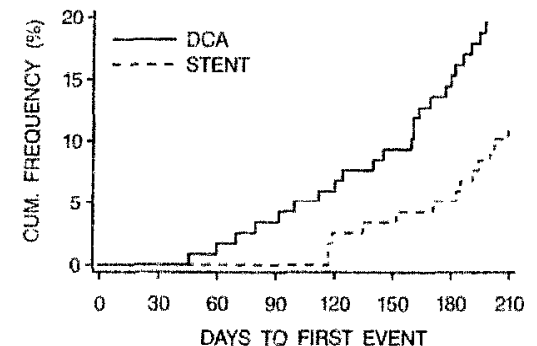

Tigure 2. Cumulative curves for target lesion revascularization (repeat angioplasty or coronary artery bypass surgery). Fewer patients in the stent group than in the atherectomy group needed revascularization of the target artery $(\mathrm{p}=0.05)$. Abbreviations as in Figure 1.

lumen diameter at follow-up. Both models can be described by the following equations:

Absolute loss $=-0.35-0.24$ vessel size +0.63 gain

$$
\text { + 0.58 MLD pre + 0.16 LAD + 0.22 de vice. }
$$

Minimal lumen diameter at follow-up $=0.35+0.24$ vessel size

$$
\text { + 0.37 gain + 0.42 MLD pre - 0.16 LAD - } 0.22 \text { device, }
$$

where $\mathrm{LAD}=$ left anterior descending coronary artery lesion, MLD pre = minimal lumen diameter before the procedure; atherectomy $=1$ and stenting $=0, \mathrm{LAD}$ lesion $=1$, non- $\mathrm{LAD}$ lesion $=0$.

A linear relation was observed between immediate gain and late loss in the two groups, with a steeper gain/loss regression line slope in the atherectomy group (0.50) than in the stent group (0.30) $(p=N S)$.

Immediate and late outcome aiter matching for both procedural outcome and bsseline characteristics (Table 4, Fig. 3). Matching for procedural outcome as well as lesion location and vessel size and lesion severity and procedural outcome identified 75 pairs of matched patients with successful atherectomy or stenting. By virtue of this matching protocol, vessel size and minimal lumen diameter before and after the procedure in the atherectomy and stent groups were similar $(3.06 \pm$ 0.43 vs. $3.05 \pm 0.42 \mathrm{~mm}, p=0.93 ; 1.09 \pm 0.25$ vs. $1.08 \pm$ $0.24 \mathrm{~mm}, \mathrm{p}=0.98$; and $2.41 \pm 0.29$ v. $2.42 \pm 0.28 \mathrm{~mm}, \mathrm{p}=$ 0.84 ), respectively. Therefore, the values for immediate lumen gain achieved with atherectomy and stenting were comparable $(1.33 \pm 0.37$ vs. $1.34 \pm 0.34 \mathrm{~mm}, \mathrm{p}=0.86)$. Patients in the atherectomy group had a significantly greater late loss during follow-up $(0.75 \pm 0.57$ vs. $0.52 \pm 0.44 \mathrm{~mm}, \mathrm{p}<0.006)$ so that the residual minimal lumen diameter at follow-up was significantly smaller after atherectomy than after stentitg (1.66 $0.53 \mathrm{vs}, 1.90 \pm 0.47 \mathrm{~mm}, \mathrm{p}<0.004$ ). Likewise, atierectomy yielded a higher percent diameter stenosis at follow-up ( 43 $17 \%$ vs. $36 \pm 12 \%, \mathrm{p}<0.004)$. Additionally, the restenosis rate (diameter stenosis at follow-up $>50 \%$ ) after stenting was significantly lower thar after atherectomy $(12 \%$ vs. $32 \%, \mathrm{p}=$ $0.00026)$

The multivarigte models to predict late loss and residual diameter at follow-ap were found to be
Table 4. Comparison of Quantitative Angiographic Data of 150 Matched Patients Who Underwent Atherectomy or Stent

\begin{tabular}{|c|c|c|c|}
\hline & $\begin{array}{l}\text { Alherectomy } \\
(\mathrm{n}=75)\end{array}$ & $\begin{array}{c}\text { Stentíng } \\
(\mathrm{n}=75)\end{array}$ & $\begin{array}{c}p \\
\text { Value }\end{array}$ \\
\hline Reference dimeter pre (mm) & $3.06 \pm 0.43$ & $3.05 \pm 0.42$ & 093 \\
\hline \multicolumn{4}{|l|}{ Minimal lumen diameter (mm) } \\
\hline Pre & $1.09 \pm 0.25$ & $1.08 \pm 0.24$ & 0.98 \\
\hline Post & $2.41 \pm 0.29$ & $2.42 \pm 0.28$ & 0.84 \\
\hline Follow-up & $1.6 \pm 9.53$ & $1.90 \pm 0.47$ & 0.0035 \\
\hline \multicolumn{4}{|l|}{ Diameter steinsis (\%) } \\
\hline Pre & $64 \pm 8$ & $64 \pm 7$ & 0.94 \\
\hline Post & $25 \pm 7$ & $22 \pm 7$ & 0.0064 \\
\hline Follow-up & $43 \pm 17$ & $36 \pm 12$ & 0.0035 \\
\hline \multicolumn{4}{|l|}{ Lumen loss (nm) } \\
\hline Absolute & $0.75 \pm 0.57$ & $0.52 \pm 0.44$ & 0,0056 \\
\hline Retative & $0.25 \pm 0.18$ & $0.18 \pm 0.14$ & 0.0082 \\
\hline Restenosis rate $(\%)$ & 32 & 12 & 0.0003 \\
\hline Lesion length (mm) & $6.88 \pm 2.34$ & $7.40 \pm 2.24$ & 0.71 \\
\hline Curvature value pre & $16.5 \pm 6.7$ & $15.7 \pm 5.7$ & 0.83 \\
\hline Symmetry index pre & $0.4 ! \pm 0.25$ & $0.46 \pm 0.23$ & $0.9 \%$ \\
\hline Area plaque pre $\left(\mathrm{mm}^{2}\right)$ & $9.63 \pm 4.62$ & $9.70 \pm 4.24$ & 0.75 \\
\hline
\end{tabular}
Implantation for Similar Lesion Severily and Procedural Outome

Data presnted are mean value \pm SD. Abbreviations as in Table 2 .

Absolute loss $=-0.74-0.18$ vessel size +0.68 gain

$$
+0.76 \mathrm{MLD} \text { pre }+0.13 \mathrm{LAD}+0.24 \text { deviec. }
$$

Minimal lumen diameter at follow-up $=0.75+0.17$ vessel size

$$
\text { + } 0.32 \text { gain + 0.27 MLD pre - 0.13 LAD - 0.24 device, }
$$

where MLD pre = minimal lumen diameter before the procedure, $\mathrm{LAD}=$ left anterior descending coronary artery lesion, atherectomy $=1$ and stenting $=0,1 \mathrm{AD}$ lesion $=1$, non-LAD lesion $=0$.

After matching for procedural outcome, the greater loss observed after directional atherectony is reflected by the finding in multivariate analysis of a significant independent effect of the procedure used, whereby less late loss and greater minimal lumen diameter at follow-up is predicted for stent implantation.

\section{Discussion}

In this study, we compared the immediate and long-term clinical and angiographic effects of successful directional atherectomy and stent implantation for primary coronary artery lesions. The major findings of this study are threefold: 1) In matched patients with similar lesion severity and location, stenting is associated with a significantly larger mmediate Iumen, which is preserved during follow-up and is reffected by a concomitant reduced need for target lesion revascularizations during the 1st 6 months; 2) when the procedural result and baseline characteristics are matched, stent implantation is found to provide a superior late angiographic ontcome dite to significant less lunen renarrowing than after atherectomy; and 3) these findings may refect a device-specific effect on urmen 

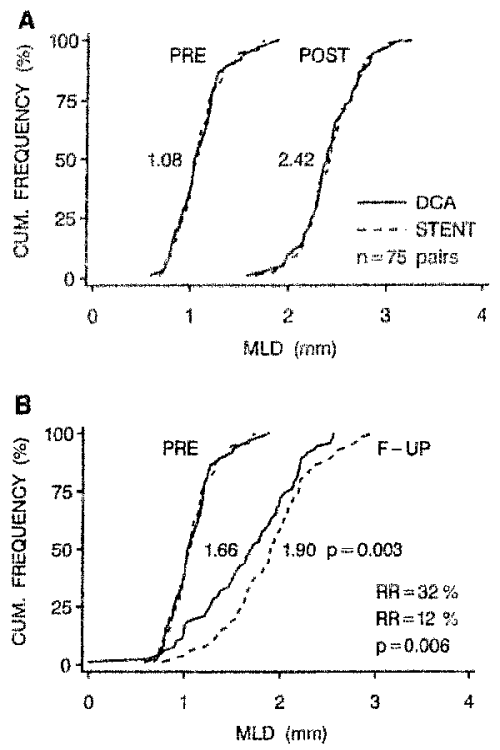

Figure 3. Graphic display of the immediate (A) and late (B) results after atherectomy and stenting in patients who were matched for lesion location and severity and inmediate gain $(n=75$ pairs). As displayed, the matching process was adequate, with superimposition of the distribution frequency curves of the minimal lumen diameter before and after atherectomy and stenting indicating similar pre- and postprocedural stenosis severity irrespective of the device deployed. Abbreviations as in Figure 1 .

renarrowing, independent of baseline characteristics or immediate procedural result.

Matching. To overcome the limitations in design of previous comparative interventional studies, we applied the previously validated concept of matching $(7,8,15,19,20)$ to the atherectomy and stent groups to evaluate and compare the effect of the interventional devices used on long-term angiographic and clinical outcome. In particular, the confounding affects of unequal vessel size and immediate lumen gain, which tave been shown to be independent predictors of restenosis $(4,5,9)$ and which have not been controlled in such studies, are avoided by this matching technique. Matching for the immediate result of intervention provides the possibility to objectively evaluate for a specific device effect, which was not possible in randomized trials, because the postprocedural results in the treatment groups were significantly different. Furthermore, matching a study group with a reference patien group of sinilar characteristics can compensate for some of the limitations of nomrandomized studies such as population heterogeneity (21). However, prospective randomized trials are traditionally regarded as the method of choice for comparing longterm outcome of different interventional procedures because case selection is potentially limited in such trials. Despite a pote.uial patient selection bias in matching studies, our atherectomy and stent patient groups had angiographic characteristics and an inmediate outcome comparable to hose of patients in several reported studies (Coronary Argioplasty Versus Excisional Atherectomy Trial [CAVEAT], Canadian
Coronary Atherectomy Trial [CCAT], BElgian NEtherlands STENT study [BENESTENT] and STent REStenosis Study [STRESS] (10-13). Thus, the findings in our comparative study may be applicable to patients selected for stenting or atherectomy and may be useful ia planning future trials.

Determinants of a favorable long-term outcome. When our group $(7,8,22)$ first studied the differences between restenosis after atherectomy and balloon angioplasty in a matched series, we not oniy observed a linear relation between immediate gain and late loss but also recognized that the slope of this regression line may represent an index of lumen renarrowing specific for each treatment modality. In a subsequent matching study (20), we further extended this observation and could indeed demonstrate that the process of lumen renarrowing was dependent not only on the extent but also on the mechanism of lumen improvement. These observations may implicate that a beneficial late outcome can be achieved by using a device that can associate a large immediate gain with a favorable relation between the degree of vessel wall injury and vessel wall response. In the present study, we compared the two available interventional devices that can consistently achieve a large immediate gain and found that the long-term outcome after stent implantation is significantly superior to that after atherectomy. A superior immediate gain achieved by stenting in patients matched only for baseline characteristics indicates that the improved angiographic outcome of stenting may be due to the combination of the extent and possibly the mechanism of lumen increase.

Why might stenting be superior to atherectomy? The comprehensive analysis of long-term outcome of stent implantation and atherectomy suggests that the scaffolding effect of stenting may lead to less lumen loss and a larger late lumen at follow-up than are achieved with the debulking mechanism of directional atherectomy in matched patients. Multivariate analysis confirmed the significant independent influence of the device used whereby less late loss and a larger lumen diameter at follow-up was predicted for stent implantation compared with directional atherectomy. In a well-controlled serial IVUS study, Mintz et al. (23) found a significant difference in the ultrasound aspect of lumen renarrowing after different transcatheter treatment strategies. In particular, stented lesions exhibited virtually no geometric remodeling but restenosis consisted predominantly of intimal hyperplasia, whereas remodeling appeared to be the main mechanism of restenosis in nonstented lesions. In fact, their study suggests a devicespecific effect on restenosis with less arterial recoil after stenting than after other interventions. Kinura et a. (personal communication) subsequcatily dorumented the tine course after stenting and atherectomy by usirg serial ultrasound measurements. They also found a different interrelation between remodeling and hyperplasia in that stenting was not associated with immediate or late recoil whereas patients with atherectomy exhbited a geometric remodeling process (decreatse if eximai clastic mombrane) that was already present at 1 month of follow-up and ongoing at 6 nonths. These ultrasound observations support our data and suggest that a 
lower restenosis rate after stenting may be the result of less vascular recoil. Indeed, earlier observational angiographic studies have demonstrated that this beneficial effect may be secondary to less elastic recoil (24) or to the restoration of the "Glagovian balance" between plaque and lumen area (25). Furthermore, by using coronary angioscopy and ultrasound techniques, Baptista et al. (26) demonstrated that, compared with atherectomy, stenting reduces the amount of trauma to the vessel wall, which ultimately may lead to a reduced vessel wall healing response (i.e., renarrowing).

Therefore, the favorable stent effect found in our study concurs with preliminary angioscopic $(27,28)$ and ultrasound $(26,29)$ observations and suggests a favorable relation between vessel wall injury (smooth circular wall configuration) and vessel wall healing response (reduced geometric remodeling) and suggests the importance of the scaffolding action of stenting. If larger studies confirm this observation, the clinical importance is that trials of restenosis prevention attempting to nevent the formation of intimal hyperplasia may particularly affect patients with stenting because intimal hyperplasia may be the dominant mechanism of restenosis. It seems unlikely that this favorable effect of stenting is attributable to a difference in treatment strategy (optimal stenting versus less optimal atherectomy) because this effect is avoided by matching for both baseline characteristics and outcome. The postatherectomy lumen diameter found in our series is comparable to that observed in the CCAT and CAVEAT trials $(10,11)$ although smaller than in the series of Kuntz et al. $(1,6)$, whereas our stent results are comparable to those reported in the BENESTENT, STRESS and Palmaz-Schatz Stent Study trials $(12,13,30)$. Such an observation does not influence the conciusions of the present study because the linear relation between immediate gain and late loss is maintained at all levels of gain, showing a favorable effect (lower slope value) for stenting when compared with atherectomy.

Clinical implications. The favorable angiographic outcome of stenting is further underlined by a significant reduction in the clinical need for target vessel revascularization. In accordance with Baim and Kuntz (31), we have refrained from asing the composite "atay event" clinical end point criteria to compare stenting with atherectomy to avoid potentially confounding factors induced by cardiac events not related to the type of interventional device used. By using such "filtered clinical end points" (31), we found an agreement between quantitative angiographic follow-up and the late clinical course, emphasizing the need for a dual arproach (angiographic and thinical follow-up) in that quantitative angicgraphy demonstrates the mechanistic explanation of the favorable stent results, whereas clinical follow-up provides the clinical implications of this finling. The $14 \%$ restenosis rate after sucessful stenting found in this stury is identical to the $14 \%$ restenosis rate of patients wilh succossfuliy stenting in the BENESTENT study (i.e., successlut stent innusatation without subacute coclusion) and comparabie to the findings of the BENESTENT II pilot phase (32).
Summary and conclusions. In matched patients, suecessful stent implantation provides a more favorable long-term angiographic outcome with a reduction in restenosis rate and in need for subsequent revascularization compared with directional atherectomy. This favorable effect is related not only to a larger immediate gain but also to a device-specific effect, whereby less renarrowing is provoked by stent implantation for a given degree of immediate gain.

Limitations of the study. Matching of prospectively col lected patients is retrospective in nature and may have led to a selection bias such as the selection of larger vessels. Inherent to the purpoze of this study, only patients who underwent a successful procedure were matched and included in this study, and we acknowledge that the results apply to a restricted group of patients who had a successful procedural outcome after undergoing atherectomy or stenting.

Whether the favorable stent effect observed in this study is due only to a scaffolding effect or could also be due to a difference in anticoagulant therapy, acute recoil or postprocedural vessel wall configuration is beyond the scope of this study. However, various reports (33-35) have ruled out an effect of anticoagulation, whereas in this study the effect of acute recoil was minimized by the use of a meticulous approach, as described earlier $(7,20)$. Criticism of the "suboptimal result" in the atherectomy group may be valid in view of the very latest opinions that a postprocedural stenosis $<20 \%$ must be achieved. However, such criticism applies equally to the stent group, and we believe it does not detract from the findings of a device-specific effect of stenting in the context of similar immediate results. Confirmation of these findings in the future among optimally treated lesions may he required. In fact, our data underscore the need for optimal results, especially for atherectomy, to accommodate late lumen renarrowing.

\section{Appendix}

Process of Automated Matching for Angiographic

\section{and Clinical Characteristics}

To compare the results of successful atherectony and successful stent intalantation, all consecutive patients from the atherectomy and stent data sels were natched, creating pairs with a patient from each tata set The variables and criteria for matching are deseribed in Metheds, under "Matehing process." Technicaly, the creation of matched pairs is as follows. First, a Cartesian product of the two data sets is mad, from which all pairs are determined that fultill to the matehing criticia. The resuit of this ss the "set of eligible pairs." On the basis of the matchisg criterio a mathing score for each pair is calculated, which is an indication of the degree of similatily. As it is possibie for the patients of one data set to be coupled to many members of the other hata set, the process then goes in an iterative way: first, the best

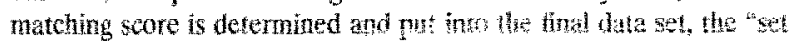

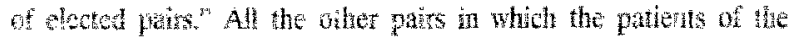
selected pair participate are then discarded trom the set of etgibio pairs. This protess is repested for the rematning patients. The parr with the bes. matching score is determined and transferpel to the set 
of elected pairs, until eventually there are no eligible pairs remaining so that all patients are matched according to the aforementioned matching criteria.

\section{References}

1. Kuntz RE, Gibson CM, Nobuyosin M, Baim DS. Gencratized nodel of reatenosis after conventional balloon angioplasty, stenting and directional atherecturny. I Am Coll Cardiol 199321:1525.

2. Kunz RE, Saffon RD, Carrozza JP, Fishman RF, Mansour M, Baim DS. The importatice of tisute suminal diameter in determining restenosis after coronary atherectomy or stenting. Circulation 199:;86:1827-35.

3. Foley DP, Melkert R, Serruys PW. Influence of coronay vessel size on renarrowing process and late ngiographic outcone after successful balloon angiop:asty. Circulation 199:, 0:1239-51.

4. Fishman $R F$, directional coronny atherectomy: predictors of restenosis. $J$ Am Coll Cardic x.m. $1101-10$.

5. Prym 11, se Cerare NB, Pinkerton $\mathrm{C}$, et al. Quantitative analysis of factors influenting late lumen loss and rcatenosis after dirctional coronary athereciomy. Am J Cardiol 1993:71:552-7.

6. Kintz RE, Hinuhara T, Robertson GC, Safian RD, Simpson JB, Baim DS. Influence of vessel selection on the observed restenosis rate after endolumir 1 s stenting or directional atherectony. Am J Cardiol 1992;70:1101-8.

7. Umans $V_{4}$, Hermans W, Foley DP, et a! Restenosis after directional coronary atherecionny and balloon angioplasty: comparative analysis based on matched lesions. J Am Coll Cardiol 1993;21:1382-90.

8. Serruys PW, Folcy DP, Kirkeeide RL, King SB III. Rentenosis revisitedinsights provided by quantitative coronary angiography. An Heart 31993 ; 126:1243-67.

9. Umans VA, Robert A, Foley DP, el al. Luminal renarrowing after directional coronary atherectony: multivariate analysis of long-term outcome and renurrowing process. J Am Coll Cardiol 1994;22:49-59

10. Tonol EJ, Leya $r$, Pinkerton $C A$, et al. A conparison of directional atherectomy with coronary angioplasty in patients with coronary artery disease. N Engl J Med 1993;329:221-7.

11. Adelman AG, Coten M, Kimball BP, et al. A comparison of directional atherectony with balloon angioplasty for lesions of the left anterior descending coromry artery. $\mathrm{N}$ Engl I Med 1993;329:228-33.

12. Serruys PW, de Jaegere P, Kiemeneij F, et al. A comparison of balloomexpandable-stent implantation with balloon angioplasty in patients with curonary artery disease. N Engl J Med 1994;331:489-95.

33. Fishman M, Leon M, Bain D, et al. A randonized comparison of coronarysient placement and balloon angioplasty in the treament of coronaty artery 4iscase. N Engl I Med 1994:331:496-501.

14. The MERCATOR study group. Does the new angiotensin converting enzyme inhibitor cilazapril prevent restenosis after percutaneous translumi nal coronary angioplaty? The tesulis of the MERCATOR study: a multicenter randomized double-blind placebo-controlled trial. Circulation 1992; 86:100-î.

15. Umans VAWM, Beatt KJ, Rensing BJWM, Hermans WRM, de Feyter PJ, Sernys PW. Comparative quantitative angiographic analysis of directional wromary aherectomy and baloon coronaty angioplasty. Am 5 Cardiol $1991 ; 68: 1556-63$

16. Kente D, Hanse i, Singer $\mathrm{Cl}$, ef al. Comparative validation of cunntitative coronary angicgraply systems: results and inplications from a multicenter study asing a standardized approach. Circulation 1995; 912174-83.

17. Auster WG, Elwards JE, Frey $\mathrm{RL}_{2}$ et al. A reportigg system in patunts evaluated for grading of coronary artery disease. Report of the Ad Hoc Committee for Grading Coronary Artery Disease, Council on Cardiovascular Surgery, American Heart Association. Circulation 1975;51:7-40.

18. Study Group, European Atherosclerotic Society. The recognition and management of hyperlipidaemia in adults: a policy statement of the European Alherosclerotic Society. Eur Heart J 1988,9571-600.

19. do Jaegere FJ, Statuss BH, we Feyter PJ, Surwapanta H, Serruys PW. Stent versus balloon angioplasty: matching based on QCA, a surrogate for randomized studics? An? Heart J 1993;125;310 -9.

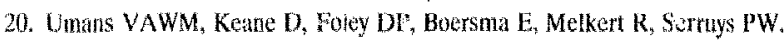
Optinal use of directional coronary atherectomy is rezquired to ensure long-tem angiographic benefit: a study with matched procedural outcome after atherectoriy and angioplasty. J Am Coll Cardiol 1994;24:1652-9.

21. Glantz SA. It is all in the numbers. J Am Coll Cardiol 1993;21:835-7.

22. Serruys PW, Foley DP, de Feyter PJ. Restenosis adter coronary angioplasiy: a proposal of new comparative approaches based on quantitative angiography. Bi Heart J 1992;69:417-24.

23. Mintz $\mathrm{G}$. Pichard $\mathrm{AD}$, Kent $\mathrm{KM}$, et al. Endovascular stents reduce restenosis by eliminating geonetric arterial remodeling: a serial intravascular ultrasound sudy [abstract]. J Am Coll Cardiol 1995;25;36A.

24. de Jacgere PPT, Serruys PW, van Fs GA, et at. Recoil following Wiktor stent implantation in native coronary arteries. Am J Cardiol 1992:69:598 -602.

25. Serriys PW, Strauss BH, van Beusekom HM, van der Gitissun WI. Stenting of coronary arteries: has a modern Pandora's box been opened? I Am Col Cardiol 1991;17:143B-54B.

26. Baptista J, Umans V, di Mario C, Eccaned J, de Feyter PJ, Serruys PW Mechanisms of luminal enlargement and quantification of vessel wall traume following balloon coronary angioplasty and directional coronary atherectomy. A study using intracoronary ultrasound, angioscopy and angiography. Eur Heart J 1995;16:1603-12.

27. Umans VAWM, Baptista J, di Mario C, von Birgelen C, de Feyter PJ, Serrlys PW. Angiographic, ultrasonic and angioscopic assessment of the coronary artery wall and lumcn area configuration after directional atherectomy: the mechanism revisited. Am Heart J 1995;130:1135-43.

28. Ueda $\mathrm{Y}$, Nanto $\mathrm{S}$, Komamura K, Kodama K. Neointimal coverage of stents in human coronary arteries observed by angioscopy. J Am Coll Cardiol 1994;23:341-7.

29. Painter JA, Wong SC, Mintz GS, Popma J, Pichard AD, Satler LF. Does stent recoil contribute to restenosis? A serial intravascular ultrasound study [abstract]. Circulation 1994,90 Suppl LI-163.

30. Savage $M P$, Fishman DL, Schatz $\mathrm{RA}_{\mathrm{s}}$ et al. Long-tarm angiographic and clinical outcome after implantation of a balloon-expandable stent iiz the native coronary circulation. J Am Coll Cardiol 1994;24:1207-12.

31. Baim DS, Kuntz RE. Appropriate uses of angiographic follow-up in the evaluation of new technologies for coronary interventiuns. Circulation 1994:90:2560-3.

32. Emanuelsson $\mathrm{H}$, Serruys PW, Belardi 3 , et al. Clinical experience with heparin-coated stents--the BENESTENT if pilot phase I [abstract]. I Ain Coll Cardiol 199; $25: 181 \mathrm{~A}$

33. Thornton MA, Gruentzig AR, Holiman J, King SB III, Douglas JS. Cotunadin and aspirin in the prevention of recurrence after transiminal coronary angioplasty: a randomized study. Circulation 1984;69:721-7.

34. Ellis S, Roubin G, Willentz J, Douglas IS Jr, King SB III. Effect of 18 iso 24-hour heparin adruinistration for prevention of restenosis after uncomplcated coronary angioplasty. An Hear J 1989:1177777-82.

35. Faxon D, Spiro T, Minor $S$, et al. Enoxaparin. a low molecular weight heparin, in the prevention of restenosis after ingioplasty: results of a double blind randomized tria? [ahstract! J Am Coll Cardiol 19\%2,19 suppl A:258A. 